\section{Plight of Wei Jingsheng}

SIR - We wish once again to direct the attention of the world scientific community to the dire plight of Wei Jingsheng, a political prisoner in the People's Republic of China. Imprisoned 13 years ago (on 16 October 1979) for prodemocratic writings, Wei is reported by confidential sources to be in poor health under harsh conditions, and possibly in danger of dying before completing his 15-year sentence.

As oceanographers, our concern was aroused by Chinese pamphlets calling for Wei's release found in a bottle by one of us (R.S.) in June 1990, on the west coast of Vancouver Island, British Columbia, Canada. This finding, once communicated to Beijing, provides Deng Xiaoping with an honourable justification for pardoning Wei Jingsheng before his sentence - and his health - expires.

After analysis (described in a manuscript submitted to Eos for publication), we conclude that the bottle was one of many released by Taiwanese activists shortly after Wei's imprisonment. In itself, the bottle is scientifically unremarkable. The inferred course of the bottle from its probable release off the islands of Quemoy or Matsu close to the Chinese mainland is consistent with known ocean currents as verified by computer simulation. Probably 50 per cent of the bottles reached their intended target of mainland China, and bottles containing similar literature have been reported from coastal Japan.

The significance of the finding lies in the fact that the bottle was found by an oceanographer and transmitted to a colleague (C.C.E.) studying drifting objects. We estimate that fewer than one per cent of the bottles released would have reached the sparsely populated northern coast of North America more than $10,000 \mathrm{~km}$ away. Most such notes, even when found, are never translated, let alone interpreted.

We call Deng's attention to a passage in the Japanese legend, The Tale of the Heike, that he could cite as a precedent for releasing Wei. In the year 1177 , the priest Yasuyori was exiled for political subversion to an island $100 \mathrm{~km}$ offshore. From his exile, he released 1,000 stupas (thin wooden boards offered as graveside memorials), each bearing his name, the date and two poems. Against steep odds, one stupa was found by a priest on the mainland. He transmitted it to Yasuyori's family and thence to the emperor and to Kiyomori, head of the Heike, who had ordered Yasuyori's exile. Two years later, upon the birth of a grandson and heir, Kiyomori pardoned Yasuyori.

We recognize the formidable obstacles to obtaining Wei's release. His fellow scientist Fang Lizhi petitioned Deng on Wei's behalf in a letter in January 1989. Influential organizations such as Asia Watch, Committee to End the Chinese Gulag and Amnesty International have been working hard for the freedom of Wei and numerous other Chinese prisoners for many years.

Nevertheless, we hope that Deng will view this rare finding and deciphering of a message in a bottle by scientific 'priests' - and our communication of it to the latter-day 'emperor' in keeping with the 800-year-old Asian legend - as an omen and an opportunity to pardon and possibly spare the life of Wei Jingsheng.

Curtis C. Ebbesmeyer (Evans-Hamilton, Inc., 731 N. Northlake Way, Suite 201 Seattle, Washington 98103, USA); $\mathbf{W}$. James Ingraham Jr (National Oceanic and Atmospheric Administration, Seattle, Washington 98115, USA); Richard McKinnon (Asian Languages and Literature, University of Washington, Seattle, Washington 98195, USA); Akira Okubo (Marine Science Research Center, State University of New York, Stony Brook, New York 11794, USA); Richard Strickland (Washington Sea Grant Program, University of Washington, Seattle, Washington 98105, USA); Dong-Ping Wang (Marine Science Research Center, State University of New York, Stony Brook, New York 11794, USA); Peter Willing (Water Resources Consulting, Bellingham, Washington 98226, USA)

\section{Women in science}

SIR - We are pleased that, in your comment $^{1}$ on the practice of the National Science Foundation to require evidence of the participation of women in scientific conferences supported by public funds, you recognize that the practice is laudable, but you underestimate the magnitude and subtlety of the challenges faced by women in science, especially in relation to meetings.

Although the numbers of women studying and teaching science in colleges and universities are increasing, they are still under-represented in the higher academic ranks of tenured positions ${ }^{2}$. Part of the explanation is that to gain tenure one must demonstrate the respect of one's colleagues, which is in part measured by activity at meetings, especially by invited participation.

In scientific communities, as elsewhere, informal networks of colleagues effectively preside over their respective fields. When sponsoring or proposing a meeting, these networks strongly influ- ence who is invited to contribute and often identify appropriate speakers from their ranks. Thus such networks tend to function, often unwittingly, as closed units, connecting people who share an intellectual pedigree and giving to meetings a restricted view of the potential intellectual breadth of a discipline. More subtly, because such restricted meetings may serve to galvanize a field, they further narrow the field's mindset, and strengthen the network that created the meeting.

Entering such a network from the outside is difficult for both men and women, but one important mechanism for circumventing this and other problems is through mentors ${ }^{3}$, established professionals in the field who advocate the merits of an outsider and his or her ability to further a scientific field. The problem lies in developing a mentor relationship. This requires personal contact with professionals in the field, which is most easily established by active participation at meetings. Unless the circle is broken, the representation of women in science will not increase.

Increasing the participation of women in scientific conferences is one way to facilitate the entry of women into the controlling networks, to help their research programs excel and to increase their entry into tenured positions.

\section{J. Engel}

\section{J. J. Flynn}

P. R. Crane

S. Lanyon

Center for Evolutionary

and Environmental Biology,

Field Museum of Natural History,

Chicago,

IIlinois 60605, USA

1. Nature 359, 92 (1992).

. Benditt, J. (ed.) Science 255. 1363-1388 (1992)

3. Gibbons, A. Science 255, 1368 (1992).

\section{Wrong book}

SIR - There is nothing like reading the original sources. In the Opinion piece discussing the Vatican's grudging resurrection of Galileo (Nature 360, 2; 1992), you presume that the Catholic Church's stand was based on "the account of the Creation in Genesis". There is in fact no mention in that text of the motion of the Earth or the Sun. The reference you want is from Joshua 10:12, "Sun stand thou still". The Church's argument was that these words would not have been spoken had the Sun not been moving.

\section{Robert J. Wyman}

Yale University,

Department of Biology,

Kline Biology Tower,

PO Box 6666,

New Haven, Connecticut

06511-8112, USA 